\title{
Os dilemas da economia solidária: um estudo acerca da dificuldade de inserção dos indivíduos na lógica cooperativista*
}

\section{Solidary Economy's Dilemmas; a study on the difficulty of inserting individuals into cooperative logic.}

\author{
Raquel de Oliveira Barreto ${ }^{1}$
}

Ana Paula Paes de Paula

\section{Resumo}

Este artigo tem como objetivo contribuir para o debate na área da Economia Solidária. Fundamentando-se nas idéias de Guerreiro Ramos e Maurício Tragtenberg, buscou-se analisar as dificuldades encontradas pelos indivíduos para se inserirem na lógica cooperativista. Para isso, realizou-se um estudo de caso na COOPETEX, no qual foram analisados aspectos como a vivência dos princípios cooperativistas, a participação e a autogestão, bem como a presença dos valores e práticas características do modelo capitalista de produção. Foi possível identificar uma desvalorização dos princípios que norteiam o movimento cooperativista e que a autogestão existe apenas enquanto discurso. Constatou-se também que os valores e métodos capitalistas são amplamente utilizados, o que torna a cooperativa uma reprodução das empresas convencionais. $A$ partir dos resultados obtidos foi possível observar o quanto a mudança de postura dos cooperados é vital para que a cooperativa funcione de forma legítima.

Palavras-chave: Economia Solidária, Cooperativas, Teoria Crítica

\section{Abstract}

This article aims to contribute to the discussion in the area of Solidary Economy. Based on the ideas of Guerreiro Ramos and Maurício Tragtenberg, the work analyzed the difficulties found by individuals to be inserted in the cooperative logic. In order to reach its objective, a case study was made in COOPETEX, in which were analyzed aspects like the existence of the cooperative principles, the participation and the automanagement, as well as the presence of the values and characteristic practices of the capitalist model of production. It was possible to identify a devaluation of the principles which guides the cooperative movement and that automanagement exists only as a discourse. Also, it was perceived that capitalist values and methods are widely used, which makes the cooperative a reproduction of the conventional enterprises. From the obtained results, it was possible to conclude that cooperative members need to change their way of acting in order to provide legitimacy for cooperative's functioning.

Keywords: Solidary Economy, Cooperative, Critical Theory

\footnotetext{
As autoras agradecem o apoio da FAPEMIG e do CNPQ ao desenvolvimento desta pesquisa

Graduanda em Administração pela Universidade Federal de Minas Gerais - UFMG. Endereço: Faculdade de Ciências Econômicas - UFMG .Av. Antônio Carlos, 6627/sala 4062 - Belo Horizonte - Minas Gerais - Brasil - CEP 31270-901. E-mail:admraquelf@hotmail.com

2 Doutora em Ciências Sociais pela Universidade Estadual de Campinas. Pós-Doutora pela Fundação Getúlio Vargas - SP. Professora Adjunta da Universidade Federal de Minas Gerais - Deparatamento de Ciências Administrativas. Endereço: Faculdade de Ciências Econômicas - UFMG - Av. Antônio Carlos, 6627/sala 4033 - Belo Horizonte - Minas Gerais - Brasil. CEP:31270-901.E-mail:appaula@face.ufmg.br.

Artigo submetido em abril e aceito setembro de 2008
} 


\section{Introdução}

Este artigo pretende contribuir para os estudos na área de Economia Solidária através de uma análise da importância de uma inserção consciente na lógica cooperativista para o sucesso deste tipo de empreendimento. A escolha de uma cooperativa como objeto de estudo se deu em função desta ser considerada a representação máxima da Economia Solidária (SINGER, 2002). A partir de um enfoque no cooperado, buscou-se compreender as diferenças de postura e da relação indivíduo-trabalho neste contexto, que se caracteriza por ver a economia não somente pela ótica do mercado.

Atualmente discute-se com freqüência o desemprego no Brasil, já que este é uma realidade no país e implica em uma deteriorização cada vez maior da qualidade de vida das pessoas. Em meio às intensas modificações sofridas pelo mercado de trabalho, o risco de perder o emprego em função do fechamento de empresas vem contribuindo para que o número de cooperativas esteja em constante crescimento.

Segundo dados da Organização das Cooperativas Brasileiras (OCB), em 2004 as cooperativas somavam 7136, já em 2005 esse número crescera para 7518, e em 2006, para 7603. Porém, segundo França Filho e Laville (2004), apesar das causas acima explicitadas serem realmente as de maior recorrência, é importante destacar que estes períodos de crises e transformações também abrem espaço para questionamentos acerca do trabalho e dos valores que o permeiam. E desses questionamentos podem surgir iniciativas como as cooperativas ideológicas (VIETEZ; DAL RI, 2001), ou seja, aquelas que são criadas espontaneamente e que mais se aproximam do modelo ideal no que diz respeito aos princípios e vivência da Economia Solidária.

Por esse e outros motivos, estudos no campo da Economia Solidária têm alcançado cada vez mais destaque e importância nos dias atuais. Despertou-se o interesse em buscar formas econômicas alternativas ao capitalismo já que este, como explicita França Filho e Laville (2004), fracassou em sua promessa de expansão econômica aliada à igualdade e prosperidade social. Para esses autores, uma forte evidência da incapacidade do capitalismo de satisfazer os aspectos sociais foi a necessidade do Estado se posicionar enquanto figura central protetora: o Estado do Bem Estar Social.

Para a compreensão do sentido de Economia Solidária, faz-se necessária uma desconstrução da concepção de economia preponderante atualmente (FRANÇA FILHO; LAVILLE, 2004). Isso significa conceber a economia de mercado apenas como uma dentre as demais formas de comportamento econômico, a saber, reciprocidade, domesticidade e redistribuição (POLANY, 1983 apud FRANÇA FILHO; LAVILLE, 2004). A partir dessa visão de economia plural, um dos conceitos de Economia Solidária pode ser definido como um conjunto de iniciativas da sociedade civil que possuem objetivos econômicos, mas que visam, acima de tudo, à disseminação de valores como a democracia e a igualdade, bem como o estreitamento dos laços sociais (FRANÇA FILHO; LAVILLE, 2004; SINGER, 2002).

Os valores do sistema capitalista, baseados na lógica do mercado, têm cada vez mais invadido espaço na vida das pessoas. E estes não se restringem à esfera econômica, mas ultrapassam-na atingindo áreas mais profundas e substantivas do ser humano (FRANÇA FILHO; LAVILLE, 2004). O resultado dessa invasão é tão significante que os indivíduos não concebem outra imagem de si mesmos senão aquela de agentes desse sistema. Agem como atores de uma peça em que não conseguem distinguir o momento no qual estão nos bastidores e que não é mais preciso atuar, isso porque vivenciam o papel em tempo integral.

Pode-se destacar a crítica de Guerreiro Ramos (1981), de que uma característica preocupante do sistema capitalista é a redução da existência humana ao âmbito do trabalho, ou seja, os indivíduos não se dedicam a outros aspectos de sua vida senão àqueles ligados ao seu sustento. Discute-se, portanto, a mudança de postura e percepção necessárias para a inserção na Economia Solidária, cuja palavra de ordem é solidariedade. Este sistema distingue-se dos demais à medida que se baseia em diferentes princípios, no qual a atividade econômica é apenas um meio já que o fim a que se propõe é muito mais amplo e envolve o aprimoramento do ser humano enquanto ser social. 
Este artigo está estruturado em cinco seções, incluindo esta introdução. A segunda seção, logo a seguir, consiste na fundamentação teórica do estudo, abrangendo o cooperativismo e algumas reflexões sobre o sistema capitalista. A metodologia utilizada para a realização da pesquisa é explicitada na terceira parte para que, na seção subsequiente, apresente-se a análise dos resultados obtidos. Na última seção, constam as considerações finais e sugestões para novas pesquisas.

\section{Fundamentação teórica}

\section{O Cooperativismo e o fenômeno da Economia Solidária: Contextualização}

Segundo França Filho e Laville (2004), o primeiro passo para se compreender a Economia Solidária é a desconstrução do conceito de economia disseminado na sociedade capitalista. Os autores se basearam em Karl Polany (1980) para desenvolver esse argumento, já que este explicita quatro formas de interação econômica: a domesticidade, a reciprocidade, a redistribuição e o mercado. Os mesmos expõem que o projeto da Economia Solidária deve se estruturar a partir de uma hibridação entre essas economias, e que o desafio é justamente reunir em uma só proposta o que cada uma delas têm de positivo. Essa forma plural de se compreender a dinâmica econômica permite que a Economia Solidária estabeleça novos parâmetros que desmistifiquem a idéia de que a riqueza e felicidade são resultados diretos da lógica do mercado (FRANÇA FILHO; LAVILLE, 2004).

Estes autores definem a Economia Solidária como um fenômeno caracterizado por iniciativas de grupos civis autônomos, que visam a desempenhar atividades econômicas de maneira diferente daquela praticada pelo sistema capitalista. A sua proposta consiste na busca por objetivos econômicos através da manutenção de laços pessoais e da disseminação de princípios como a solidariedade e a democracia legítima. Tal fenômeno é relativamente recente e, portanto, necessita de estudos mais profundos a fim de delinear claramente o conceito e desdobramentos do mesmo (CANÇADO, 2005). Singer (2002) defende a idéia de que a Economia Solidária é uma proposta superior ao sistema atual, não no sentido de gerar comparativamente maiores rendimentos, mas uma forma de melhorar a qualidade de vida das pessoas. $\mathrm{O}$ autor argumenta que somente na medida em que ela for concebida dessa maneira, poder-se-á discutir as perspectivas acerca do seu desenvolvimento.

O movimento cooperativista tem como marco inicial o ano de 1844, no qual fundou-se a Rochdale Society of Equitable Pionner, considerada a mãe das cooperativas. O empreendimento surgiu em Rochdale, na Inglaterra, o qual consistia em uma cooperativa de consumo de operários da indústria têxtil que se expandiu consideravelmente ao longo dos anos. Inicialmente, o projeto dos pioneiros de Rochdale era a constituição de uma aldeia comunista na qual as atividades estariam voltadas para a subsistência e o excedente seria comercializado. No entanto, tal projeto perdeu força, mas, enquanto cooperativa, se expandiu rapidamente com a abertura de um moinho, em 1850, e de uma tecelagem e fiação em 1854, passando a se caracterizar também como cooperativa de produção (LIMA, 2004; SINGER, 2002).

Singer (2002), como explicitado anteriormente, argumenta que a cooperativa, especificamente a de produção, seria o empreendimento ideal da Economia Solidária. O autor caracteriza como cooperativas de produção aquelas que reúnem trabalhadores com o objetivo de produzir bens ou serviços. No Brasil, é a partir dos anos 1980 que este tipo de cooperativa destacou-se, em grande parte devido ao cenário de crises econômicas e da disseminação das idéias neoliberais que culminaram no fechamento de empresas e em um quadro de desemprego estrutural (LIMA, 2004).

As cooperativas diferenciam-se das empresas capitalistas justamente em função dos seus princípios e valores. Estes possuem diferentes fundamentos, sendo eles o humanismo, a liberdade, a igualdade, a solidariedade e a racionalidade. Teoricamente, os cooperados são movidos por valores éticos como honestidade, responsabilidade social e interesse no bem coletivo (BENATO, 2006). Os princípios do cooperativismo definidos na gênese do movimento em 1844, embora atualmente pareçam simples, representaram uma realização importante para a identidade e o delineamento do movimento como um todo (SINGER, 2002). 
A Aliança Cooperativa Internacional (ACI) aprovou em 1995, em um Congresso realizado em Manchester na Inglaterra, a versão mais recente da Carta de Princípios da ACI, sendo eles: a adesão voluntária e aberta; controle democrático por parte dos membros; participação econômica dos associados; autonomia e independência; educação, capacitação e informação; cooperação entre as cooperativas e interesse pela comunidade. Constatou-se que tais princípios não foram amplamente modificados, pois se mostram coerentes com os ideais dos pioneiros de Rochdale e mantêm o caráter igualitário e democrático da proposta cooperativista (BENATO, 2006).

Ao analisar essas diretrizes, percebe-se que a todo momento, mesmo que não explicitamente, a questão da necessidade de uma inserção consciente na lógica cooperativista se faz indispensável. $\mathrm{O}$ fato de que o ingresso em uma cooperativa baseia-se na livre opção do indivíduo pressupõe o seu interesse em aderir à proposta, o que é correlato à participação nas decisões e à busca por um constante aprimoramento profissional. $\mathrm{O}$ desenvolvimento do interesse pelo cooperativismo também, enquanto movimento, implica na busca pelo seu fortalecimento por meio do incentivo de relações intercooperativas, bem como do empenho em fazer com que a vivência dos seus princípios signifique uma transformação muito além da geração de renda e emprego, e sim uma mudança de caráter social. Discute-se, portanto, como realizar tais objetivos que exigem uma determinada visão do indivíduo acerca da realidade, se este permanece submerso nos valores de uma economia tão antagônica.

O princípio central que caracteriza os empreendimentos solidários é o da autogestão, visto que este consiste em uma participação efetiva dos cooperados. As assembléias gerais são realizadas com o intuito de dar voz aos participantes, sendo que durante a mesma, questões que vão desde o nível estratégico e gerencial até as que orientam a adesão de novos sócios são discutidas e resultam em diretrizes de funcionamento para a cooperativa. Portanto, a participação dos cooperados é essencial para que as decisões tenham realmente um caráter coletivo e, da mesma forma, para que a responsabilidade pelas implicações das mesmas seja igual para todos (JUNQUEIRA; TREZ, 2004).

\section{Críticas ao sistema capitalista e a questão da inserção na lógica cooperativista}

Polany (1980) critica a idéia de Adam Smith que o homem, por natureza, busca o lucro e o ganho privado, já que o primeiro considera o Homo Economicus fruto da modernidade. Guerreiro Ramos (1981) também refuta a idéia de que motivações econômicas caracterizam a essência humana e ainda expõe que é essa a definição do homem em que se baseia a sociedade capitalista, na qual para se ter sucesso, o indivíduo deve se comportar como tal.

A invasão dos valores da economia de mercado já podia ser observada pelo interesse de Frederick Taylor e Henry Ford, autores clássicos da administração, de controlarem aspectos particulares da vida de seus funcionários, suas famílias e condutas perante a sociedade. Essa intromissão já indicava a característica da economia capitalista de subjugar as demais áreas da vida em sociedade, fazendo com que estas se articulassem em função daquela, e não o contrário. Dessa forma, o mercado capitalista, desde o início, atuou como uma força modeladora dos indivíduos.

Tragtenberg (1974) também teceu críticas às teorias administrativas no sentido de denunciar o seu caráter explorador, compreendendo-as como produtos dinâmicos de um determinado contexto histórico, capazes de se adaptarem às necessidades do mesmo. Assim como Ramos (1981), o autor explicita a dominação presente no modelo taylorista-fordista que se evidencia por meio dos métodos de controle social. Tais ações buscam mascarar o conflito entre capital e trabalho, tornando inviável a prática dos princípios autogestionários capazes de propiciar a emancipação humana. As transformações introduzidas pelo Taylorismo-Fordismo caracterizaram-se por uma intensa especialização e alienação do trabalhador, que deixou de dominar todo o processo produtivo e passou a dedicar-se apenas a uma parte dele. Dessa forma, o capital tem a possibilidade de explorar o trabalhador na medida em que este se torna uma peça facilmente substituível. 
Ramos (1981) destaca o conceito de política cognitiva, sendo esta definida como a prática de distorcer conceitos com a finalidade de manipular a forma como as pessoas vêem a realidade. $\mathrm{O}$ autor expõe esta como uma forma de destruir o senso comum, ou seja, de fazer com que as pessoas absorvam regras e opiniões sem nenhuma reflexão sobre as mesmas. Ele atribui a tal política o fato da sociedade se conformar de maneira tão acrítica com um sistema de caráter totalmente dominador, e é justamente essa neutralidade com que todas as proposições deste são aceitas que corrobora o sucesso da política cognitiva.

Posteriormente aos autores da Organização Científica do Trabalho, a Escola das Relações Humanas propõe a introdução de um caráter humanista à organização econômica. Ramos (1981) argumenta que este se tratava de um falso humanismo à medida que não consistia em uma preocupação com o ser humano enquanto indivíduo, mas sim em buscar formas de manipulá-lo a fim de que gerasse maior rendimento ao capital. Mais uma vez a política cognitiva se mostrou importante, permitindo que, cada vez mais, o indivíduo se tornasse parte da organização, ou melhor, que esta fosse essencial para a sua vida. Tragtenberg (1980), neste mesmo sentido, critica a Escola Comportamental ao expor que os métodos participativos são por ela utilizados apenas para dar aos funcionários a ilusão de que a opinião dos mesmos é relevante no processo decisório, enquanto, na verdade, as decisões já foram previamente tomadas.

Ramos (1981) ressalta a idéia de que não é possível que as pessoas alcancem sua auto-realização na sociedade capitalista. Ele expõe, inclusive, que um dos maiores prejuízos dessa posição central que a organização ocupa na vida dos indivíduos é o risco de que cada vez mais eles se distanciem de si mesmos, passando a moldurar-se segundo um modelo pré-fabricado.

A Economia Solidária se apresenta como uma alternativa a essa sociedade dominada pelos princípios do mercado. A consciência por parte dos indivíduos das armadilhas criadas pela economia capitalista poderia culminar no surgimento de empreendimentos solidários originais, ou seja, aqueles que funcionam de acordo com a proposta da Economia Solidária. Tal proposta passa certamente pela idéia de que a existência humana não se resume à atuação enquanto agente organizacional, mas compreende aspectos muito mais profundos e substantivos dos indivíduos. Porém, o caminho para se alcançar sucesso neste tipo de empreendimento envolve a conscientização acerca desses fatores, tornando essa questão muito mais complexa do que simplesmente posicionar-se como espectador, ou seja, exige mudanças significantes dos indivíduos.

Nesse sentido, as empresas autogestionárias, como é o caso das cooperativas, buscam superar o modo de produção capitalista através da modificação das relações de trabalho. Em algumas organizações solidárias já estudadas, existe um empenho muito grande para que os seus componentes tenham uma visão ampla do processo produtivo, o que pode ser alcançado através de um rodízio de funções, por exemplo (VIETEZ; DAL RI, 2001). Mas para isso é necessária tanto uma preocupação com a educação quanto uma mudança da visão dos trabalhadores que, mesmo inseridos na Economia Solidária, muitas vezes não se desvinculam das características do capitalismo.

Vietez e Dal Ri (2001) demonstram claramente através de seus estudos esse forte traço cultural do sistema capitalista que ainda persiste dentro das organizações autogestionárias. Estes relatam que alguns associados desejam a reintrodução de métodos de controle do período Taylorista-Fordista e que são comuns atualmente, como os relógios de ponto. Esse desejo provém justamente do fato de que outros associados não estariam se dedicando da mesma forma ao trabalho, realidade esta que retrata falta de maturidade e identificação com a proposta no qual estão inseridos. É válido destacar que são vários os fatores, inclusive externos, determinantes para o bom desempenho deste tipo de empreendimento, os quais este trabalho não pretende discutir. O dilema da inserção na lógica cooperativista é o foco principal da pesquisa, a qual não desconsidera os demais aspectos fundamentais às organizações cooperativas.

Como explicita Singer (2002), o desenvolvimento de uma Economia Solidária depende, em grande parte, da disposição das pessoas de mudar sua forma de ver a economia e aprender a colocar em prática seus princípios. Em muitos trabalhos científicos em que foram pesquisadas cooperativas e instituições autogeridas, como as experiências descritas por Vietez e Dal Ri (2001), Lima (2004) e Pinto, Silva e Irigaray (2006), constatou-se a 
falta de conhecimento e concretização dos princípios, e muitos relataram que o espírito cooperativista não se encontrava consagrado. $\mathrm{O}$ fato de que muitas cooperativas surgem a partir do fechamento de empresas, cujos funcionários optam por fundá-las a fim de não perderem o emprego, contribui em grande parte para que não exista a observância dos princípios na realidade das organizações, já que não é uma formação de cunho ideológico.

Como explicitado anteriormente, é necessário reconhecer a complexidade dessa questão para não incorrer no erro da ingenuidade, ou seja, acreditar que a transição do indivíduo para uma economia com princípios diferenciados ocorreria de forma natural, realidade esta que já pode ser observada. Fundamentando-se nas idéias de Guerreiro Ramos (1981) e Tragtenberg (1980), pode-se dizer que a constatação do fato de que os valores da economia de mercado invadiram de tal forma espaços substantivos da vida humana, permite o prognóstico de que a inserção bem sucedida em um novo contexto exigirá mudanças nas mesmas dimensões.

\section{Metodologia}

Com a finalidade de classificar a pesquisa, pode-se utilizar a taxionomia apresentada por Vergara (2000), a qual estabelece dois critérios, qualificando-a em relação aos meios e aos fins. Quanto aos fins, esse estudo possuiu um caráter descritivo, e quanto aos meios, consistiu em pesquisa de campo, documental e estudo de caso. A pesquisa classificou-se como descritiva na medida em que teve o intuito de relatar o funcionamento e as características da cooperativa e, a realização de análises de documentos fornecidos pela mesma atribuiu à pesquisa a característica documental (VERGARA, 2000).

A investigação empírica tornou o estudo uma pesquisa de campo, a qual foi concretizada, com certo grau de profundidade, na COOPETEX, Cooperativa de Produção de Artigos Têxteis, portanto, um estudo de caso. Segundo Roesch (1999), o estudo de caso possibilita um aprofundamento a respeito de um fenômeno de acordo com o contexto no qual ele se insere, podendo analisá-lo sob vários ângulos. O estudo de caso se mostra vantajoso na medida em que é possível tanto fazer uma análise mais ampla, quanto enfatizar determinadas áreas e aspectos situacionais (BERG, 1998 apud PINTO; SILVA; IRIGAY, 2006).

A fim de selecionar uma organização a ser estudada, realizou-se um levantamento inicial por meio do cadastro da OCEMG - Organização das Cooperativas de Minas Gerais - a respeito das cooperativas de produção de Minas Gerais. O resultado desta busca revelou a existência de apenas três cooperativas do setor no estado, dentre as quais está a COOPETEX. Tal cooperativa foi escolhida a partir do critério de localização e disponibilidade em relação à realização da pesquisa.

A principal técnica de coleta de dados foi a realização de entrevistas com roteiros semi-estruturados, visando uma compreensão ampla das relações e organização do empreendimento selecionado. O roteiro foi montado de acordo com os objetivos da pesquisa e foi um resultado direto da investigação teórica inicialmente realizada, assim como sugere Goldenberg (2000). A observação direta também foi utilizada com o intuito de contribuir para a análise do problema, já que esta é fundamental para entender o funcionamento do ambiente, bem como captar informações que não são abordadas pelos respondentes.

Para a obtenção de dados relevantes para a pesquisa, buscou-se entrevistar cooperados que desempenhassem diversas funções dentro da cooperativa, compreendendo todos os níveis hierárquicos existentes. Desta forma, como explicitado por Rubin e Rubin (1995, apud PINTO; SILVA; IRIGAY, 2006), a identificação de pessoaschave que fornecem diferentes perspectivas bem como a atenção para questões como o fato do entrevistado estar disposto a contribuir com a pesquisa e conhecer sobre o que esta pretende explorar, são fatores importantes que devem ser considerados. De acordo com tais ponderações, as seguintes pessoas foram entrevistadas: o presidente, o diretor-tesoureiro, a secretária/auxiliar administrativa, o encarregado de turno e onze pessoas diretamente ligadas à produção tais como fiandeiras, operadores de máquinas, embalador, mecânico e expedidores. 
As entrevistas foram realizadas na própria cooperativa e registradas com um gravador a fim de manter a integridade dos dados. As respostas foram transcritas e analisadas pela técnica de análise de conteúdo. Para a compreensão e interpretação dos dados, definiram-se três unidades de análise da mesma forma provenientes dos objetivos da pesquisa, sendo elas: participação, princípios cooperativistas e presença dos valores capitalistas. Para a interpretação e apresentação dos resultados referentes às três unidades definidas, buscou-se confrontar as informações obtidas por meio dos instrumentos utilizados: a observação direta, entrevistas semiestruturadas e a análise-documental.

\section{Objeto de estudo: COOPETEX}

\section{Da falência à origem de uma cooperativa}

A COOPETEX surgiu a partir de um arrendamento da companhia industrial Itaunense. Esta última foi uma grande indústria do setor têxtil, fundada em maio de 1911, na cidade de Itaúna, Minas Gerais. Em janeiro de 1999, a empresa interrompeu definitivamente o seu funcionamento, o que resultou na extinção de um número significativo de postos de trabalho. Entretanto, por meio da iniciativa de um ex-funcionário da fábrica, formulou-se uma proposta de arrendamento, a qual culminou, meses depois, na constituição da COOPETEX.

O ex-funcionário idealizador da cooperativa, o qual desde então se encontra no cargo de presidente, reuniu algumas pessoas interessadas em aderir à proposta, todos da mesma forma provenientes da Itaunense. A cooperativa inicialmente foi constituída por vinte e quatro cooperados, número este que hoje é de cento e sessenta pessoas. Em março de 2000 foi decretada a autofalência da Itaunense que, por consequiência, causou o fechamento da cooperativa. No entanto, diante de sua função social, a decisão de um juiz possibilitou a reabertura da mesma, que ainda no regime de arrendamento, comprometeu-se a pagar à massa falida da empresa, o valor mensal referente a $8 \%$ do faturamento do respectivo mês.

A COOPETEX é caracterizada como uma cooperativa de produção, a qual tem como objetivo específico o processamento de fibras de algodão, poliéster, viscose, entre outros, com o intuito de transformá-las em fios e tecidos (ESTATUTO COOPETEX). Inicialmente, pelo fato de não possuírem capital suficiente para adquirir matérias-primas e iniciar sua própria produção, os cooperados optaram por um caminho alternativo, oferecer o serviço de facção.

Devido ao fato de atuar em um mercado altamente competitivo, o uso de tecnologia torna-se um diferencial importante. Esta é uma das principais dificuldades enfrentadas pela COOPETEX, já que a maquinaria utilizada é antiga, o que faz com que a mesma esteja em desvantagem em relação às empresas do setor. Desta forma, decisões sobre investimentos, um bom funcionamento da produção, a busca pela qualidade dos serviços, todos esses aspectos tornam-se indispensáveis para a sobrevivência da cooperativa. Nesse sentido pode-se destacar a importância da consciência dos cooperados acerca do seu papel dentro da mesma, visto que os fatores acima explicitados estão diretamente ligados à participação e gestão do empreendimento.

\section{Interpretação de uma realidade específica}

Os tópicos seguintes consistem nas três unidades de análise mais relevantes obtidas por meio do exame e interpretação do conteúdo das entrevistas bem como da observação realizada. Tais unidades relacionam-se diretamente aos objetivos da pesquisa, pois constituem questões fundamentais à proposta cooperativista.

\section{Princípios cooperativistas}

Os princípios cooperativistas, como explicitado anteriormente, são os pilares para a construção de uma cooperativa enquanto empreendimento ideal da Economia Solidária (SINGER, 2002). Diante disso, a presença dos mesmos torna-se indispensável, visto que são responsáveis pela identidade de uma cooperativa e funcionam 
como diretrizes de funcionamento da mesma. Para a discussão desta unidade de análise, buscou-se observar a consciência dos cooperados acerca dos princípios, e concomitantemente, identificar se cada um dos mesmos se faz presente no dia-a-dia da COOPETEX.

Observou-se, na cooperativa, um profundo desconhecimento dos princípios do cooperativismo, principalmente dentre aqueles diretamente ligados à produção, os quais não souberam, sequer com palavras próprias, opinar sobre o assunto. A falta de consciência dos princípios por parte dos cooperados evidencia uma inserção da mesma forma inconsciente na proposta da Economia Solidária, sendo este, inclusive, outro conceito não compreendido corretamente pelos mesmos. Apesar do fato dos conceitos não serem reconhecidos, buscou-se verificar se estavam presentes na prática. Para isso, a observação se fez um instrumento importante, na medida em que complementou as impressões individuais obtidas por meio das entrevistas.

O primeiro ponto analisado diz respeito à entrada de novos cooperados que, de acordo com o princípio da adesão livre e aberta, é voluntária a todos aqueles aptos a oferecer os seus serviços e dispostos a respeitar o regimento interno. Na COOPETEX a adesão é espontânea, mas ocorre somente após a aprovação do candidato pelo Conselho de Ética, o qual avalia de acordo com os seguintes critérios: o candidato não deve estar trabalhando em nenhuma empresa, deve ser conhecido de algum cooperado e este ser seu abonador, além de possuir experiência no ramo têxtil. Argumenta-se que tais exigências, de certa forma, desconfiguram o princípio acima explicitado, visto que, caso não sejam analisados os casos específicos, possuem um caráter excludente.

A autogestão, um dos mais importantes pilares do cooperativismo, é tratada em vários artigos do estatuto, principalmente no que diz respeito aos direitos dos cooperados. Porém, o que se pôde observar é que o controle democrático existe de fato enquanto discurso, questão esta que será abordada com maior profundidade posteriormente, na análise da participação. De modo geral, observou-se que a administração se concentra nas mãos do presidente e, que os diversos fatores que levam ao desinteresse dos cooperados em relação à gestão do empreendimento, fazem com que este se distancie cada vez mais do modelo autogestionário.

A COOPETEX demonstrou ser independente no sentido de atuar sem interferência de qualquer outra instituição, como a prefeitura ou o estado. No que diz respeito à participação econômica, os cooperados recebem o denominado pro-labore, o qual é definido mensalmente em função das sobras obtidas. Ao serem questionados sobre tal participação, os cooperados alegaram que “(...) o salário é bom”, o que de certa forma evidencia a percepção empregado-empregador característica das empresas convencionais.

Outro princípio que caracteriza o movimento cooperativista é a constante busca pelo aperfeiçoamento profissional, bem como uma preocupação quanto à educação. Na COOPETEX, são poucos os que participam de cursos de capacitação e a respeito do cooperativismo, visto que a cooperativa não os promove. $\mathrm{O}$ que se pôde perceber é que estes últimos são freqüentemente ofertados pela OCEMG, porém, na maioria das vezes, não são considerados atraentes pelos cooperados. No que se refere à questão da educação, o presidente relatou o mau resultado de tentativas de implantação do Telecurso 2000:

"Em duas oportunidades nós tivemos a iniciativa de implantar aqui o telecurso 2000, para melhorar o nível cultural mesmo, porque aqui muitas pessoas nem terminaram o $1^{\circ}$ grau... Nós arrumamos sala, professores, tudo aqui dentro da fábrica. Para surpresa minha, $90 \%$ não teve interesse”. (trecho da entrevista com o presidente)

Um aspecto muito importante que envolve o movimento cooperativista é a sua existência enquanto proposta de caráter social. Diante disso, teoricamente, espera-se que tais empreendimentos desenvolvam atividades que demonstrem essa preocupação com a sociedade, principalmente no intuito de disseminar os mesmos valores que os caracterizam, como a democracia e a solidariedade. Na COOPETEX observou-se a preponderância de uma concepção equivocada a respeito do que seria tal faceta social, pois, segundo os entrevistados, o fato de contribuir financeiramente com algumas instituições como a ACCON - Associação de Combate ao Câncer do Centro-Oeste de Minas - e a APAE - Associação de Pais e Amigos de Excepcionais, demonstra o interesse da 
mesma pela comunidade. Além deste tipo de prática, de cunho assistencialista, a cooperativa não promove outras ações que visam a realizar aquilo que a diferencia das empresas convencionais. Entretanto, para os cooperados, tais atitudes são suficientes para que a cooperativa cumpra seu papel social.

O estabelecimento de relações intercooperativas destaca-se como uma forma de ajuda mútua, visto que a realização de negócios bem como a troca de experiências representam um caminho interessante para fortalecer o movimento como um todo. Tal tipo de relação não se apresenta como um objetivo da COOPETEX, o que é evidenciado pela sua pouca expressividade. Em relação à troca de informações, observa-se mais uma vez que a cooperativa assume uma postura reativa, visto que a comunicação com as demais somente se dá por meio de eventos promovidos pela OCEMG.

Desta forma, o estudo da COOPETEX corrobora as conclusões obtidas por Junqueira e Trez (2004), os quais identificaram uma certa desvalorização dos princípios do cooperativismo nos empreendimentos por eles analisados. Segundo os autores, tal fato se torna um entrave para o desenvolvimento da cidadania e para a constituição do capital social. No caso da cooperativa em questão, a participação, a democracia e o estabelecimento de laços interpessoais não se encontram entre as suas prioridades, situação esta que reflete em todo o funcionamento da mesma, que será analisado mais profundamente no tópico a seguir.

\section{Identificação dos Princípios Cooperativistas na COOPETEX}

\begin{tabular}{lll}
\hline Princípio & Foi identificado? & Justificativa \\
\hline 1) Adesão voluntária e aberta & PARCIALMENTE & $\begin{array}{l}\text { Adesão voluntária, mas depende de } \\
\text { aprovação do Conselho de Ética }\end{array}$ \\
\hline 2) Autogestão & MUITO POUCO & O controle não é democrático (discurso) \\
\hline 3) Participação econômica & SIM & $\begin{array}{l}\text { Cooperados recebem pro-labore (divisão } \\
\text { das sobras) }\end{array}$ \\
\hline 4) Autonomia e independência & SIM & Cooperativa atua sem interferências \\
\hline 5) Educação, capacitação e informação & POUCO & Existem poucas atividades neste sentido \\
\hline 6) Cooperação entre as cooperativas & MUITO POUCO & Existem raras atividades neste sentido \\
\hline 7) Interesse pela comunidade & NÃO & Não existem atividades neste sentido
\end{tabular}

Fonte: Autoria própria

\section{A raiz do problema: valores e práticas contraditórias}

Segundo Vietez e Dal Ri (2001), a busca por superar o modo capitalista de produção destaca-se como uma característica das empresas autogeridas. Tal busca se justifica pelo antagonismo entre seus princípios e valores, os quais exigem uma transformação também das relações de trabalho. Para esta unidade de análise, buscou-se compreender o funcionamento da COOPETEX, bem como identificar se este é compatível com a proposta da Economia Solidária. Foi possível constatar o quanto os valores e métodos capitalistas ainda se fazem presentes, o que torna a cooperativa, salvo em alguns aspectos, uma reprodução das empresas convencionais. 
Um primeiro ponto a ser destacado refere-se aos objetivos da cooperativa. Estes que deveriam, de acordo com a definição da Economia Solidária, priorizar, além de aspectos econômicos, a disseminação de valores como a solidariedade, mostram-se erroneamente definidos. Tal argumentação é baseada na declaração do presidente:

\begin{abstract}
"O objetivo principal, principal mesmo, é econômico. Não vou falar que é social, porque o social você só faz com resultados. Não existe social sem resultados econômicos, eu não conheço. O nosso foco é econômico, prestar serviços para as pessoas e ter lucro. Dizem que cooperativas não podem ter lucro, mas eu acho que isso é conversa, porque com lucro, ou sobra como chamam no cooperativismo, é que uma empresa faz o social. Então o nosso foco é econômico, e com bons resultados econômicos é que a gente faz o social”. (trecho da entrevista com o presidente)
\end{abstract}

Ao analisar o trecho explicitado pode-se argumentar que é coerente, visto que esse comportamento é que possibilitaria a sua sobrevivência em meio ao sistema capitalista predominante. Entretanto, a questão a ser discutida refere-se ao fato de que, tão ou mais importante que os objetivos econômicos, deve ser o caráter social das cooperativas. A observação deste aspecto envolve a compreensão de que existe uma grande diferença entre a concepção do que é a função social de uma cooperativa e a de uma empresa capitalista intitulada como socialmente responsável. Portanto, as contribuições financeiras a instituições realizadas pela COOPETEX são insuficientes para desempenhar o seu papel de colaborar para o desenvolvimento de uma comunidade pautada em valores como a solidariedade.

É importante destacar que o fato de que a COOPETEX surgiu a partir do fechamento da Companhia Industrial Itaunense, tem influência direta na organização e funcionamento da mesma. A maior parte dos cooperados são ex-funcionários da Itaunense, na qual trabalharam durante vários anos e, por isso, trouxeram para a cooperativa muitos costumes e valores. O que se pôde perceber é que os entrevistados não identificam diferenças significativas entre o período em que eram empregados e agora, em que são cooperados. Alguns destacam apenas que, na cooperativa, possuem uma responsabilidade maior quanto aos resultados do seu trabalho. Entretanto, ressalta-se que essa visão acerca da realidade é um processo em construção, pois, muitos problemas surgiram e ainda aparecem resultantes da incompreensão da mesma.

"De vez em quando eles ainda tem aquela raiz de funcionários da Itaunense, porque eles gostam muito de serem empregados no momento de olhar os seus direitos. Isso é difícil de acabar, porque está enraizado na pessoa, durante anos e anos como empregados. Hoje são cooperados, são os donos né? Mas ainda agem como empregados, principalmente no que diz respeito aos direitos" (sic). (trecho da entrevista com o presidente)

Por meio da expressão “(...) aquela raiz de funcionários da Itaunense...”, utilizada pelo presidente no trecho explicitado, pode-se observar claramente o quanto os cooperados ainda se mostram vinculados à empresa falida. Discute-se o fato de que as mudanças no ambiente bem como nas relações de trabalho não podem ser percebidas justamente porque as próprias pessoas não mudaram a sua postura ao se inserirem na cooperativa, isto é, a falta de consciência acerca do que constitui a proposta cooperativista faz com que a COOPETEX exista enquanto uma reconstituição da antiga Itaunense, com as mesmas instalações, pessoas e valores.

Os cooperados relataram um desconhecimento acerca do significado de cooperativa no momento em que aderiram à proposta, adesão esta que foi causada, principalmente, pela situação de desemprego. Segundo o presidente, tal motivação ainda é predominante atualmente e, portanto, a inserção na Economia Solidária não se dá em função de seus objetivos e fundamentos, mas representa uma opção frente à escassez de oportunidades de emprego. A realidade de uma adesão inconsciente aliada ao desinteresse em conhecer a essência do movimento contribuem amplamente para a perpetuação de um modelo que nem sequer caminha na direção do ideal.

Uma observação que corrobora a discussão de que a COOPETEX se encontra distante do que propõe o cooperativismo, refere-se à relação entre os cooperados. Observou-se que, ao contrário do que se supõe encontrar em organizações desta ordem, prevalece o individualismo e a desunião. 
"Não mudou... assim, sempre muda alguma coisa (referindo-se à transição da Itaunense para a COOPETEX), mas eu acho que não mudou muito. Teria que mudar... teria. Eu fiz um curso de conselho fiscal e foi falado isso mesmo, mas o mais difícil é conscientizar o pessoal. Eles pensam assim 'sou dono então não vou ajudar não...', aqui tá assim: cada um por si e Deus por todos" (sic). (trecho da entrevista com responsável por serviços gerais)

O modelo taylorista-fordista de produção se faz claramente presente no funcionamento da fábrica, em que o trabalhador é especializado e está submetido a vários métodos de controle. Um primeiro aspecto que evidencia tal realidade é a existência de uma estrutura hierárquica bem delineada, a qual define claramente os papéis dentro da cooperativa e o poder de seus respectivos representantes. Assim como explicitam Junqueira e Trez (2004), as cooperativas se caracterizam pela eqüidade e pela estrutura horizontal e, portanto, incompatível com o que foi observado. Os relatos de um encarregado de turno da produção e um mecânico explicitam a existência da subordinação não enquanto instrumento de organização, mas de controle e fiscalização das pessoas.

“(...) às vezes falta alguém e eles me chama para ficá de encarregado, aí eles (a diretoria) fala que eu tenho que cobrar, ficá em cima, mas eu não acho certo não (sic)." (trecho da entrevista com o mecânico)

“(...) na empresa, o seguinte, as punições são diferentes, por exemplo, na cooperativa você tem que ter muito cuidado para punir uma pessoa, saber como você faz isso, porque na empresa você é dono, se você não tiver satisfeito manda embora". (trecho da entrevista com o encarregado de turno)

A análise do funcionamento da COOPETEX corrobora as considerações feitas por Vietez e Dal Ri (2001) acerca da presença da cultura do sistema capitalista nas organizações autogeridas. A cooperativa utiliza-se de métodos como o relógio de ponto, com a finalidade de controlar o horário de entrada e saída das pessoas. Ao serem questionados a respeito de tal utilização, os cooperados, em sua totalidade, se mostraram favoráveis e fizeram comentários acerca da irresponsabilidade de alguns membros do grupo.

"É porque se não vira bagunça. Porque se não tiver o povo pensa que é cooperativa então 'vou chegar na hora que eu quiser"”. (trecho da entrevista com fiandeira)

“(...) no início não tinha, mas agora a gente tem até relógio de ponto. Porque, porque se não tiver controle vira bagunça, cada pessoa vai chegar em um horário diferente, aqueles que cumprem seus horários direitinho vão sair prejudicados em relação àqueles que podemos chamar de mais malandros, então, hoje nós administramos aqui como se fosse uma empresa se não, não funcionaria, viraria um caos". (trecho da entrevista com o presidente)

Pode-se observar, através dos comentários, a imaturidade de alguns cooperados frente à proposta na qual estão inseridos, isso porque assim como a presença de uma hierarquia, tais meios de controle se fazem desnecessários. Estes foram inicialmente utilizados por Taylor e Ford com o objetivo de vigiar os operários, certificar que estavam realizando corretamente suas tarefas e evitar boicotes. No caso das cooperativas, tais situações se tornam inconcebíveis já que os cooperados são co-responsáveis pelos resultados obtidos e, portanto, deveriam demonstrar interesse no bom desempenho das mesmas.

Como se pôde observar, a presença de tais técnicas de controle e da subordinação se justificam devido à compreensão equivocada de alguns cooperados acerca do sentido de serem proprietários. Isto é, a imagem de donos concebida por alguns é justamente a relacionada a uma empresa capitalista, o que implica em poder e liberdade. Desta forma, este se mostra um fator extremamente negativo, já que para o cooperativismo, a propriedade comum expressa não somente a eqüidade quanto à participação no patrimônio e nos resultados, mas também de responsabilidades frente às decisões referentes à cooperativa. 


\section{O discurso da autogestão: o papel da participação no contexto cooperativista}

A autogestão pode ser considerada uma das principais características dos empreendimentos solidários. O fato da administração ser realizada pelos próprios cooperados, como é o caso das cooperativas, implica que as decisões sejam legítimas representações da vontade comum. Pode-se afirmar que a autogestão relaciona-se diretamente aos valores democráticos, sendo que, para que a mesma se concretize, a participação é um quesito fundamental. Diante de tais motivos, este tópico objetiva a análise da participação na COOPETEX.

As assembléias constituem o símbolo do controle democrático, visto que nela são discutidos todos os assuntos relacionados à cooperativa. Na COOPETEX, as assembléias ordinárias são realizadas anualmente, próximas ao mês de março, nas quais são apresentados os balanços e os resultados obtidos no ano anterior. Caso exista algum assunto de caráter emergencial ou de extrema relevância, é convocada uma assembléia extraordinária, como por exemplo, para decisões a respeito de compras de maquinaria, as quais envolvem investimentos de altos valores.

Constatou-se que a participação na COOPETEX é relativamente baixa, pois a presença nas assembléias é, em média, de cerca de $60 \%$ dos cooperados. No entanto, é a baixa qualidade da participação o aspecto crítico. Essa realidade é preocupante, pois coloca em risco a questão do controle democrático, já que as decisões são deliberadas apenas por aqueles que se fazem presentes. Compreender os motivos da ausência dos cooperados nas reuniões se faz importante na medida em que, se forem contornados, podem contribuir para o desenvolvimento da cooperativa como um todo.

Um fator-chave que colabora para a baixa participação dos cooperados refere-se à falta de interesse de alguns no que diz respeito às decisões tomadas. Ao permanecerem com uma postura de empregados, os quais se preocupam apenas com o seu trabalho individual, ignoram o seu papel de gestores do empreendimento. Uma conseqüência preocupante desta ausência dos cooperados é a desinformação. Isso porque as assembléias têm a função de dar transparência ao que acontece dentro da cooperativa, seus negócios e implicações e, na medida em que isso não acontece, os entrevistados relatam que o ambiente torna-se propício para a desconfiança.

"Eu acho muito importante (a participação nas assembléias), porque é aberto, eles nos colocam a par de tudo que acontece dentro da cooperativa. É claro que tem aqueles que não quer saber, acontece demais. Só que eles não quer) saber ali, aí no outro dia vem os comentários, quer saber o que aconteceu, geralmente quem tá passando aumenta ou diminui, aí gera a polêmica. Mas muitos não se interessam" (sic). (trecho da entrevista com responsável por serviços gerais)

De acordo com as entrevistas realizadas, pôde-se perceber que os cooperados possuem uma concepção incompleta do que seria a participação. Para a maioria, esta consiste na possibilidade de estar presente nas assembléias e ter conhecimento do que ocorre dentro da cooperativa, o que já apresenta um grande avanço em relação às empresas convencionais. Todavia, tal princípio possui um sentido mais amplo, que consiste na construção de decisões em conjunto, no planejamento, em expressar opiniões capazes de influenciar o futuro da cooperativa.

Os cooperados consideram-se despreparados para administrar a cooperativa, principalmente por nunca terem desenvolvido atividades nesse sentido. Desta forma, julgam que os integrantes da diretoria é que são capazes de desempenhar tal função, o que é confirmado pela permanência dos mesmos na gestão da cooperativa desde a sua fundação. Relatou-se que nunca houve a formação de uma chapa que concorresse às eleições para os cargos por eles ocupados. O desinteresse se torna mais evidente a partir da observação da ata da última assembléia realizada com intuito de eleger os membros da diretoria, na qual constam a assinatura de 76 cooperados, quorum reunido após três convocações.

Ao questioná-los a respeito do funcionamento das assembléias e reuniões, observou-se que são, na verdade, consultas aos cooperados, já que a maioria das decisões são apresentadas como propostas pré-definidas. Apoiados na justificativa do despreparo, os cooperados não se sentem à vontade para discordar e propor 
mudanças, mesmo porque têm receio de não apresentarem argumentos concretos, como se pode perceber no trecho abaixo.

"Reunião mensal eles (a diretoria) perguntam, já vem praticamente pronta, eles perguntam, pode até mudar alguma coisa mais é difícil... as vezes eu posso até não concordar com alguma coisa mais eu não consigo explicar... até então é melhor confiar (sic)." (trecho da entrevista com responsável por serviços gerais)

Desta forma, pode-se considerar que a participação dos cooperados na gestão da COOPETEX existe apenas enquanto discurso. $\mathrm{O}$ fato de que os cooperados não se interessam em interferir nos rumos adotados pela cooperativa, seja por ainda se comportarem como empregados, ou por se considerarem despreparados, impedem o exercício genuíno da autogestão. A realidade é que tal contexto possibilita a atuação da diretoria, principalmente do presidente, como administrador de um negócio privado, os quais tomam decisões, fazem planejamentos e realizam os negócios que se transformarão em serviços pelas mãos de todos. Embora intitulada como cooperativa, suas características e funcionamento denunciam uma empresa convencional, que em alguns pontos, se assemelha à ideologia participacionista denunciada por Tragtenberg (1980).

\section{Busca por soluções: discussão de possibilidades}

É possível afirmar que o desconhecimento da proposta cooperativista contribui amplamente para os resultados obtidos na pesquisa. Uma opção a ser discutida trata-se da inserção do tema como conteúdo de estudo para o ensino fundamental e médio. $\mathrm{O}$ fato de se estudar o cooperativismo desde o início da vida escolar tende a tornálo um assunto cotidiano e natural à comunidade e, ao despertar o interesse das pessoas, poderia resultar na constituição de empreendimentos fiéis à proposta da Economia Solidária. É válido ressaltar que, ao tratar dos valores e fundamentos do cooperativismo, como a honestidade e a solidariedade, estar-se-á contribuindo não só para a disseminação do movimento, mas também para a construção de uma sociedade mais igualitária. Da mesma forma discute-se a introdução do tema cooperativismo no ensino superior, em cursos como Administração, Economia e Ciências Contábeis. A possibilidade do estudo dentro das universidades poderia implicar em um aprofundamento da temática, o qual seria benéfico no sentido de compreender suas dificuldades e propor soluções.

No entanto, como explicitado anteriormente, as transformações no âmbito da educação somente culminam em resultados a longo prazo. Diante das dificuldades apresentadas pelas cooperativas atuais, discutem-se caminhos pelos quais estas possam se desenvolver sem que isso signifique a inobservância de seus princípios fundamentais. Um ponto extremamente debatido é o papel do poder público neste contexto, pois, como pôde ser observado por meio do estudo da COOPETEX, tais iniciativas são insignificantes perto das necessidades expostas pela cooperativa.

A realização de iniciativas concretas por parte do poder público, como incentivos e a criação de leis que contribuíssem com o movimento, possibilitaria que as cooperativas amenizassem algumas de suas dificuldades, como o atraso tecnológico. Com a resolução de seus problemas na esfera produtiva, as cooperativas poderiam voltar sua atenção para questões que estão de certa forma esquecidas, como a sua função social. Porém, é válido ressaltar que o apoio do setor público não deve interferir na autonomia da cooperativa e que este também depende da conscientização dos cooperados. Um acontecimento ocorrido na COOPETEX comprova tal argumentação.

“A proposta da prefeitura seria levar à Câmara dos Vereadores uma proposta de doação de um terreno de $22.000 \mathrm{~m} 2$ para a cooperativa. $O$ assunto já estava bem encaminhado, com boa receptividade por parte dos vereadores. Entretanto, na Assembléia Geral Extraordinária para tratar do tema, os cooperados rejeitaram a proposta, alegando que a construção da sede acarretaria diminuição nos seus rendimentos. Dessa forma, a proposta nem foi enviada pela prefeitura à Câmara dos Vereadores". (trecho da entrevista com o presidente) 
Uma outra possibilidade interessante e viável em curto prazo é um melhor aproveitamento das oportunidades de cursos oferecidos por organizações como a OCEMG. Segundo o presidente da COOPETEX, o apoio desta instituição é muito significativo e contribui para o fortalecimento da proposta cooperativista. Porém, destaca-se que as cooperativas não devem apresentar uma postura reativa, e sim buscarem, concomitantemente, investir na conscientização dos seus cooperados, desenvolvendo seus próprios cursos e palestras ou até mesmo levando até tais organizações demandas específicas. Ao compreenderem a importância do conhecimento acerca dos princípios e valores que caracterizam a Economia Solidária, as cooperativas possivelmente obterão retornos positivos quanto à atitude de seus integrantes frente ao seu trabalho, às suas relações com os demais e aos assuntos que envolvem a cooperativa como um todo.

\section{Considerações finais}

Ao longo deste artigo discutiu-se a questão da dificuldade da inserção dos indivíduos de caráter social na lógica cooperativista. Ao compreender a importância do movimento enquanto proposta, faz-se necessário destacar o seu antagonismo em relação aos valores disseminados pelo modo capitalista de produção. Este se baseia em princípios como o individualismo e o enfoque econômico, enquanto em contrapartida, a Economia Solidária se fundamenta na solidariedade e na democracia.

A análise da COOPETEX corrobora os resultados de pesquisas que vêm sendo realizadas acerca do cooperativismo. A discussão fundamental proposta por este trabalho encontra respaldo nestes resultados, ao passo que evidenciam o quão importante é o papel do cooperado para a construção de um empreendimento fiel à sua proposta originária.

A questão da participação, da autogestão, do desenvolvimento de laços interpessoais e da superação de um modo de produção, somente se torna possível a partir do momento em que os cooperados têm consciência de que estão inseridos em uma proposta diferente da predominante. Para isso, é necessário exercitar ações e pensamentos que da mesma forma são negligenciados na atuação no sistema capitalista, como a solidariedade e $\mathrm{o}$ interesse pelo bem comum.

Como era previsto, confirmou-se a dificuldade dessa mudança de postura, que se dá inicialmente pelo desconhecimento da proposta e é agravada pela falta de interesse. Essa realidade faz com que o cooperativismo ainda precise percorrer um longo caminho para realizar os seus objetivos de alterar os parâmetros da sociedade, isto é, de demonstrar que a existência humana não se resume à atuação enquanto agente organizacional. Neste contexto, a educação no cooperativismo revela-se então uma questão fundamental.

Discute-se, portanto, a contribuição de uma visão crítica na busca pelo entendimento dos fenômenos organizacionais além daquilo que é aparente. Ao questionar os aspectos que permeiam o ambiente e as relações que o compõem, torna-se possível interpretar mais claramente a realidade. Ao conscientizar-se acerca das deformações do capitalismo e concebê-lo enquanto um sistema marcado pela dominação e alienação dos indivíduos, a busca por alternativas passa a ser uma preocupação real. Neste sentido, a Economia Solidária apresenta-se como uma delas, embora, como explicitado ao longo do trabalho, sua vivência ainda encontre dificuldades a serem enfrentadas.

É importante salientar que este estudo de caso não pode ser generalizado, pois não reflete a realidade de todas as cooperativas no país. A intenção foi alertar para os aspectos discutidos no artigo: outras pesquisas precisariam ser realizadas para demonstrar se esta dificuldade de inserção na lógica solidária se faz presente na maioria das cooperativas brasileiras. Por outro lado, o trabalho realizado demonstrou que investigações sobre os fatores críticos para a sobrevivência das cooperativas se fazem necessárias, pois seriam uma forma de contribuir para que estes empreendimentos se tornem alternativas sustentáveis. Além disso, também seria interessante um estudo acerca da influência da cultura brasileira para a configuração do movimento cooperativista no país, uma vez que evidenciaria a forma como os brasileiros se comportam frente à proposta da Economia Solidária. 


\section{Referências}

BENATO, João Virotino Azolin. o que é o cooperativismo. Disponível em: <http:// www.coopintegral.com.br/noticias.php?codigo=4>. Acesso em: 12 dezembro 2006.

BERG, B.L. Qualitative research methods for the Social Sciences. 3.ed. Needham Heigts. MA: Allyn and Bacon,1998 apud PINTO, Sandra Regina da Rocha; IRIGARAY, Hélio Arthur Reis; SILVA, Rafael Caldas Ferreira. Tu me "ensina" a fazer renda, eu te ensino a trabalhar: a organização do trabalho de uma cooperativa popular. IN: ENCONTRO ANUAL DA ANPAD, 30, Salvador, 2006. Anais... Salvador: 2006. CD-ROM.

CANÇADO, Airton Cardoso. Para a Apreensão de um Conceito de Cooperativa Popular. In: ENCONTRO ANUAL DA ANPAD, 29, Brasília, 2005. Anais... Brasília: 2005, CD-ROM.

ESTATUTO COOPETEX. Itaúna. Estatuto Social aprovado na Assembléia Geral de Constituição realizada em 29 de outubro de 1999. p.01-24.

FRANÇA FILHO, Genauto Carvalho de; LAVILLE, Jean-Louis. Economia Solidária: uma abordagem internacional. Porto Alegre: Editora da UFRGS, 2004. 199p.

GOLDENBEG, Mirian. A arte de pesquisar: como fazer pesquisa qualitativa em Ciências Sociais. 4.ed. Rio de Janeiro: Record, 2000.

JUNQUEIRA, L.A.P; TREZ, A.P. O capital social e a sobrevivência das cooperativas de trabalho. In: ENCONTRO ANUAL DA ANPAD, 28, Curitiba, 2004. Anais... Curitiba: 2004. CD-ROM.

LIMA, Jacob Carlos. O trabalho autogestionário em cooperativas de produção: o paradigma revisitado. Revista Brasileira de Ciências Sociais, v. 19, n. 56, p.46-62, out. 2004.

ORGANIZAÇÃO DAS COOPERATIVAS BRASILEIRAS. Brasil Cooperativo. Disponível em: <http://www.brasilcooperativo.com.br/DesenvolvimentodeCooperativas/RamosdoCooperativismo/tabid/80/Default.aspx >. Acesso em: 14 dezembro 2006.

PINTO, Sandra Regina da Rocha; IRIGARAY, Hélio Arthur Reis; SILVA, Rafael Caldas Ferreira. Tu me "ensina" a fazer renda, eu te ensino a trabalhar: a organização do trabalho de uma cooperativa popular. IN: ENCONTRO ANUAL DA ANPAD, 30, Salvador, 2006. Anais... Salvador: 2006. CD-ROM.

POLANYI, Karl. La grande transformation. Aux origines politiques et èconomiques de notre temps. Paris: Gallimard, 1983 apud FRANÇA FILHO, Genauto Carvalho de; LAVILLE, Jean-Louis. Economia Solidária: uma abordagem internacional. Porto Alegre: Editora da UFRGS, 2004. 199p.

POLANYI, Karl. A grande transformação: as origens da nossa época. Rio de Janeiro: Campus, 1980. 360p.

RAMOS, Alberto Guerreiro. A nova ciência das organizações: uma reconceituação da riqueza das nações. Rio de Janeiro: Editora Fundação Getúlio Vargas, 1981. 209p.

ROESCH, Sylvia Maria Azevedo. Projetos de Estágio e de Pesquisa em Administração: guia para Estágios, Trabalhos de Conclusão, Dissertações e Estudos de Casos. 2.ed. São Paulo: Editora Atlas S.A., 1999. 301p.

RUBIN, H.J. \& RUBIN, I.S. Qualitative Interviewing: the art of the hearing data. Califórnia: Sage Publications, 1995 apud PINTO, Sandra Regina da Rocha; IRIGARAY, Hélio Arthur Reis; SILVA, Rafael Caldas Ferreira. Tu me "ensina" a fazer renda, eu te ensino a trabalhar: a organização do trabalho de uma cooperativa popular. IN: ENCONTRO ANUAL DA ANPAD, 30, Salvador, 2006. Anais... Salvador: 2006. CD-ROM.

SINGER, Paul. Introdução à Economia Solidária. São Paulo: Editora Fundação Perseu Abramo, 2002. 127p.

TRAGTENBERG, Maurício. Burocracia e ideologia. São Paulo: Ática, 1974. 228p.

TRAGTENBERG, Maurício. Administração, poder e ideologia. São Paulo: Moraes, 1980. 198p.

VERGARA, Sylvia Constant. Projetos e relatórios de pesquisa em administração. 3.ed. São Paulo: Editora Atlas S.A., 2000. 92p.

VIETEZ, Candido Giraldez; DAL RI, Neusa Maria. Trabalho associado: Cooperativas e empresas de autogestão. Rio de Janeiro: DP\&A, 2001. 151p. 